\title{
Relationship Quality Among Half Siblings : the Role of Childhood Co-residence
}

\section{Tanskanen, Antti Olavi}

Turku Center for Welfare Research 2018

Tanskanen , A O \& Danielsbacka , M J E 2018 ' Relationship Quality Among Half Siblings : the Role of Childhood Co-residence ' Working Papers on Social and Economic Issues , no. 5/2018, Turku Center for Welfare Research , Turku . https://doi.org/10.1007/s40806-018-0161-9

http://hdl.handle.net/10138/311260

https://doi.org/10.1007/s40806-018-0161-9

acceptedVersion

Downloaded from Helda, University of Helsinki institutional repository.

This is an electronic reprint of the original article.

This reprint may differ from the original in pagination and typographic detail.

Please cite the original version. 
Tanskanen, A.O., Danielsbacka, M. (2019). Relationship Quality Among Half Siblings: the Role of Childhood Co-residence. Evolutionary Psychological Science, 5, 13-21. doi:10.1007/s40806-018-0161-9

\title{
Relationship quality among half siblings: The role of childhood co-residence
}

\begin{abstract}
It is argued that the childhood co-residence duration is one of the most important kin detection mechanisms among siblings and thus should influence the relationship quality between them. Using data from the German Family Panel (Pairfam) sibling module, we detect whether childhood co-residence predicts relationship quality (as indicated by the contact frequency and emotional closeness) among adult half siblings. Individuals who have co-resided with their half siblings during childhood report a better relationship quality with these siblings compared to individuals who have not co-resided with half siblings. Among individuals who have co-resided for most of their childhood with half siblings, the relationship quality is better in same-sex dyads than opposite-sex dyads. Finally, no difference in relationship quality was detected between full and half siblings in cases in which they lived together during their childhood. These findings indicate that childhood co-residence tends to regulate relationship quality among adult half siblings.
\end{abstract}

Keywords: Childhood co-residence, half siblings, kin detection 


\section{Introduction}

Inclusive fitness theory predicts that individuals invest in their close kin according to genetic relatedness, such that higher genetic relatedness predicts higher investment (Hamilton, 1964). Full siblings share approximately $50 \%$ of same genes, while half siblings share $25 \%$ of the same genes, meaning that full siblings should invest more time and other resources towards one another compared to half siblings. In line with the inclusive fitness theory, studies have shown that individuals tend to invest more in their full siblings than in their half siblings (e.g., Pollet, 2007; Tanskanen \& Danielsbacka, 2014). For instance, using German Family Panel (Pairfam) data (the same data we use in this article), a recent study found that full siblings are emotionally closer to one another and have more contact with one another compared to half siblings (Steinbach \& Hank, 2018).

In addition to differences between full siblings and half siblings, studies have shown that maternal half siblings invest more in one another than paternal half siblings (e.g., Pollet, 2007; Tanskanen \& Danielsbacka, 2014). This has been explained by childhood co-residence. Because children in Western societies usually stay with their mothers if the parents separate, it is assumed that maternal half siblings usually live together during their childhood, while not being the case for paternal half siblings. However, in present-day societies, all maternal half siblings have not been raised together, and some paternal half siblings have, meaning that the previously used measure for childhood coresidence (i.e., whether half siblings are maternal or paternal) may be an imprecise indicator. Here, we use a more precise indicator for childhood co-residence: the participants report how long they have co-resided with their half siblings during childhood. 
Childhood co-residence between siblings is an evolutionarily important factor because it serves as an important kin detection indicator. Humans do not identify a person as kin on the grounds of shared genes but instead use certain cues to detect a close relative. These cues can be either direct or indirect (e.g., Antfolk, 2014; Bressan \& Kramer, 2015). Direct cues can be physiological (e.g., facial resemblance) or psychological (e.g., personality similarity) (Krupp, DeBruine \& Jones, 2011). Most often, however, individuals have to use indirect cues of relatedness. Childhood coresidence could be the most effective indirect cue for relatedness among siblings, and it can also serve as a main impetus for incest aversion that develops between children who have been raised together. Westermarck (1921) was the first who proposed that because incest has high reproductive costs, natural selection should have produced sexual aversion towards it. Westermarck argued that childhood proximity (e.g., co-residence with sibling) is the proximate mechanism that activates incest aversion (see, e.g., Antfolk \& Wolf, 2017 for discussion). Although, Westermarck never himself empirically tested this prediction, several later investigations have provided support for Westermarck's hypothesis (e.g., Bevc \& Silverman, 1999; Lieberman \& Lobel, 2012; Talmon, 1964).

Here, we investigate whether childhood co-residence is associated with relationship quality among adult half siblings. According to evolutionary scientists, childhood co-residence duration should regulate the relationship quality among siblings in the way that those individuals who have coresided with siblings during childhood should have closer relationships with them in adulthood (Lieberman et al., 2007; Sznycer et al., 2016). Previous studies have provided support for this prediction. For instance, using data of 170 college students from the US, it was found that coresidence was a strong predictor of sibling altruism (Bressan et al., 2009). Perhaps one of the most important limitations of existing studies detecting association between childhood co-residence and sibling relationship quality is that they often used small-scale and non-representative samples. Here, 
we study whether childhood co-residence is associated with relationship quality among half siblings with large-scale data of younger adults in Germany. We assume that:

Hypothesis 1 (H1): When co-residence duration between half siblings increases, the relationship quality also improves.

In addition to this general co-residence effect, the sex of the siblings is of interest. Based on the incest avoidance perspective, childhood co-residence should regulate sibling relationships such that opposite-sex siblings become more distant compared to same-sex siblings (Lieberman et al., 2003) because the incest aversion should be present between opposite-sex siblings. Several studies have indicated that childhood co-residence is associated with sexual disgust between opposite-sex siblings (e.g., Antfolk et al., 2012; Fessler \& Navarrete, 2004). However, studies adopting incest avoidance perspective, which have tested whether sex differences exist in the case of sibling relationship quality are scarce. Here, we test associations between half sibling relationship quality, childhood co-residence and sex. We predict that:

Hypothesis 2 (H2): Among half siblings who co-resided with one another, the relationship quality is better in same-sex dyads than opposite-sex dyads.

Finally, if childhood co-residence is a key kin detection mechanism among siblings, one can predict that when half siblings have been raised together, their relationships should be similar to those of full siblings who have been raised together. This means that if individuals who have spent their childhood together are considered, the commonly found differences between full and half siblings (i.e., full siblings are closer to one another compared to half siblings) should disappear (Danielsbacka \& Tanskanen, 2015). We hypothesize that: 
Hypothesis 3 (H3): There is no difference in the relationship quality between full and half siblings when the siblings have been raised together.

\section{Data and methods}

To test these hypotheses, we use data from the Pairfam survey, which provides longitudinal data on three German birth cohorts of 1971-1973, 1981-1983 and 1991-1993. The first Pairfam round was conducted in 2008-2009, and further data have been collected annually (see Brüderl et al., 2017; Huinink et al., 2011 for the full data description). We use the fifth round of data collected in $2012-$ 2013 when the respondents were between 18 and 42 years old $(M=29.4, \mathrm{SD}=8.22)$. The fifth round of data are used because these data contain the unique sibling module. For the study purposes, we have formed separate samples, which are explained below.

With the first sample, we studied $\mathrm{H} 1$ and $\mathrm{H} 2$, which are the main hypotheses in the present study. In this sample, only participants who have half siblings were included because in the Pairfam, the question concerning childhood co-residence with siblings was not asked of full siblings. For analysis purposes, the data were reshaped into a long format form, meaning that the present dataset was constructed so that the observations are viewed from the perspective of the original respondent's half siblings. The sample resulted in a total of 1,386 observations from 886 unique respondents (i.e., approximately 1.6 half siblings per respondent).

The second sample was formulated to study the H3. This sample included 6,326 observations from 3,814 unique persons (i.e., approximately 1.7 siblings per respondent). In this sample, we have included participants who have spent their childhood with full or half siblings. In the case of half 
sibling relations, we have included all participants who reported that they co-resided with their half siblings from birth until their 18th birthday. Unfortunately, the Pairfam did not gather co-residence duration information between participants and their full siblings, as discussed above. However, Pairfam provides information concerning whether respondents have lived with both their biological parents between the respondent's birth and 18th birthday as well as information on whether the respondents' parents have separated. When respondents lived their entire childhood with biological parents who have not separated, it is also likely that their full siblings have co-resided with them, and these cases are included in the sample as a reference group to half siblings. The measure for full sibling co-residence is a rough indicator because not all may have spent their childhoods with the respondents (e.g., some may have been placed in foster care etc.). Thus, it is important to consider this when interpreting findings regarding the differences between full and half siblings. Finally, to put the findings related to $\mathrm{H} 3$ into perspective, we also show the relationship quality differences between full and half siblings when childhood co-residence is not considered, including all full and half siblings available in the data - that is, 9,748 observations from 5,663 unique participants (i.e., approximately 1.7 siblings per respondent).

Two dependent variables measuring sibling relationship quality was used in the analyses. These variables measured contact frequency and emotional closeness, which have also been used in several previous studies detecting half sibling relationship quality (e.g., Steinbach \& Hank, 2018). In the Pairfam data, contact frequency was indicated by asking the participants how often they had contact with their siblings, taking into account different types of contact, i.e., visits, telephone calls, letters, etc. (ranging from $0=$ never to $6=$ "daily"). Emotional closeness was measured by asking how close the respondents felt towards their siblings (ranging from $0=$ not at all close to $4=$ close). 
In the case of $\mathrm{H} 1$ and $\mathrm{H} 2$, the main explanatory variable measured childhood co-residence duration. In the survey, respondents were asked to report how long they had lived with their half sibling before their 18 th birthday via a five-point scale $(0=$ no time at all, $1=$ only for a short time, $2=$ less than half of the time, $3=$ more than half of the time, $4=$ entire time). In the analyses, the group that indicated "never" was used as a reference category. In the case of $\mathrm{H} 3$, the main independent variable indicated genetic relatedness between respondents and their siblings $(1=$ full siblings, $2=$ half siblings), and the group "full siblings" was the reference category.

Several variables that have been shown to correlate with sibling relationship quality in previous studies were adjusted to produce more robust results (see, e.g., Pollet \& Hoben, 2011). In the case of $\mathrm{H} 1$ and $\mathrm{H} 3$, we controlled for the respondent's age, years of education, marital status, ethnic background, birth order, number of siblings (including all living and deceased biological, half, step and adoptive siblings), sex constellation between the respondent and sibling, travel time to the sibling (ranging from $0=$ living in the same house to $6=$ three hours or more) and age difference between the respondent and sibling (Table 1). With the exception of the sex constellation variable, these factors were also controlled in the models considering $\mathrm{H} 2$ (the sex constellation variable was not included in covariates because it was included in the interaction term).

$<$ Table 1 near here $>$

We ran linear regression models in which sibling observations were nested within individual responses. Multilevel models were used because the data were clustered by siblings (i.e., the sample may have included several observations from one respondent); thus, a method that considers the non-independence of sibling relationship quality measures reported by the respondents was needed. In the Results section, we first detected associations between childhood co-residence and half 
sibling relationship quality $(\mathrm{H} 1)$ and illustrated these results by calculating the predictive margins (and 95\% confidence intervals) from the regression models. Second, we included interaction terms in the models and investigated the interactions between childhood co-residence and half sibling relationship quality by sex constellation (i.e., same-sex or opposite-sex half sibling pairs) (H2). We implicated these interaction results by using the statistical software Stata's "lincom" command, which provides a post-estimation technique that computed the combinations of coefficients. Finally, we compared the relationship quality between full and half siblings (H3) and illustrated these results by calculating the predictive margins (and 95\% confidence intervals) from the regression models.

\section{Results}

According to H1, increased co-residence duration among half siblings in childhood should be associated with increased relationship quality between them in adulthood. Figure 1 (and Table 2: Model 1) illustrates that participants who have co-resided for longer periods with half siblings during childhood also have more contact with them. Similarly, Figure 2 (and Table 2: Model 2) shows that longer childhood co-residence duration is associated with improved emotional closeness among half siblings. These findings support H1.

$<$ Figure 1 near here $>$

$<$ Figure 2 near here $>$

In addition to co-residence duration, several other factors are associated with half sibling relationship quality (Table 2). When respondents' years of education increased, contact frequency 
and emotional closeness also increased. Female-female half sibling pairs have more contact than male-male pairs. Moreover, female-female half sibling pairs have more contact with each other than male-female pairs (female-female $=$ ref, $\beta=-0.36, p<0.001$ ), and they are emotionally closer to one another (female-female $=$ ref, $\beta=-0.21, p=0.003$ ). The increased age difference between half siblings is associated with increased emotional closeness. Finally, when the travel time distance between half siblings increased, contact and emotional closeness decreased.

$\mathrm{H} 2$ predicts that childhood co-residence decreases the relationship quality more in opposite-sex than same-sex half sibling dyads. To study this prediction, we included interaction terms in the models and investigated the interactions between childhood co-residence and the sex constellation of half siblings. The results are shown in Table 3, and the interaction results are further implicated in Table 4. Participants who have co-resided with half siblings in childhood more than half of the time or the entire time have more contact with same-sex than opposite-sex half siblings. Moreover, the participants who co-resided with their half siblings for their entire childhood reported more emotional closeness to same-sex than opposite-sex half siblings. These findings are in line with H2.

$<$ Table 3 near here $>$

$<$ Table 4 near here $>$

Finally, $\mathrm{H} 3$ assumes that there should be no difference in the relationship quality between full and half siblings when siblings have been raised together. Figures 3 and 4 (and Table 5) show that when childhood co-residence is not considered, full siblings have significantly more contact with and are emotionally closer to one another compared to half siblings. However, when only participants who were raised with their full or half siblings were included, no statistically significant difference 
between full and half siblings exists. The findings are similar regardless of whether relationship quality is measured by contact frequency or emotional closeness. The results support H3.

$<$ Figure 3 near here $>$

$<$ Figure 3 near here $>$

$<$ Table 5 near here $>$

\section{Discussion}

This study investigated relationship quality among half siblings. First, it was found that participants who co-resided with their half siblings during childhood reported more contact and emotionally closer relationships with them than those who did not co-reside with their half siblings (H1). Second, among individuals who co-resided most of their childhood with half siblings, the relationship quality was better in same-sex dyads than opposite-sex dyads (H2). Third, there was no significant difference in the relationship quality that respondents reported towards full and half siblings when only sibling pairs who had been raised together were included (H3). These findings provided support for the prediction that childhood co-residence is an important kin detection mechanism and regulates the relationship quality among adult half siblings.

The present study expands the existing knowledge related to the role of childhood co-residence in influencing relationship quality among half siblings. Prior studies have investigated whether childhood co-residence is associated with relationship quality among maternal and paternal half siblings (e.g., Pollet, 2007; Tanskanen \& Danielsbacka, 2014). Although children in present-day 
Western countries more often live with their mothers than their fathers if the parents separate, all maternal half siblings have not been raised together, and some paternal half sibling have been raised together. Thus, previously used measures for childhood co-residence (i.e., whether one has maternal or paternal half siblings) can be considered an imprecise indicator. The present study shows that the increased time in which half siblings have co-resided during childhood is indeed associated with improved relationship quality between them in adulthood.

In addition, we found that increased co-residence time during childhood differentiated same-sex and opposite-sex half sibling pairs from each other. Poorer relationship quality between opposite-sex half sibling pairs compared to same-sex half sibling pairs who co-resided for most of their childhood together is in line with Westermarck's (1921) theory of incest aversion. This finding indicates that incest aversion between opposite-sex half siblings tends to influence their relationship quality in adulthood.

Our results support the assumption that living together in childhood is an important predictor for sibling relationship quality in adulthood. A comparison between full siblings and half siblings who lived their entire childhood together showed that there were no differences between the relationship quality of co-residing full and half sibling. Thus, half siblings who co-resided together throughout their entire childhood are approximately as close to one another as full siblings who co-resided together.

The present study has several strengths. One of the strengths is that the Pairfam sibling module provides retrospective information on childhood co-residence with half siblings, making it possible to investigate the role of this important kin detection mechanism. In addition, the present findings are based on a large-scale and population-based sample of younger adults. Finally, we were able to 
control for several potentially confounding factors that are known to be associated with sibling relationship quality.

The present study also has its limitations. It is possible that co-residence during the first years of life regulates half sibling relationships more than in later childhood (Antfolk \& Wolf, 2016). However, Pairfam does not have information on whether half sibling co-residence existed during early childhood or later childhood. Perhaps the two most important data limitations are that information on childhood co-residence duration was not gathered from full siblings, and there was no information on whether half siblings are maternal or paternal. Due to these data limitations, we were unable to reliably study another potentially important kin detection cue among half siblings, namely, maternal perinatal association (i.e., seeing one's own mother nurse a newborn baby) (Lieberman et al., 2007). Thus, future studies are needed to investigate the correlation between maternal perinatal association and the relationship quality among siblings with large-scale and population-based data.

In addition, because there was no direct question regarding childhood co-residence duration with full siblings, the results regarding the comparison between full and half siblings can be interpreted as directional. We have assumed that when the respondents lived their entire childhoods with both biological parents who have not separated, their full siblings also co-resided with them. This may not, however, always be the case because some full siblings may have not co-resided with one another - for instance, if one sibling has been placed in foster care. Thus, it could be that the relationship quality among co-residing full siblings is underestimated because some full sibling pairs have not been raised together. 
In sum, the present study shows that childhood co-residence tends to influence the relationship quality among younger adults who are half siblings in Germany. Moreover, among individuals who had co-resided with half siblings for most of their childhood, the relationship quality is better in same-sex dyads than opposite-sex dyads. Finally, no difference in relationship quality was detected between full and half siblings in cases where they lived their childhood together. These results indicate that childhood co-residence is an important kin detection mechanism among half siblings and tends to regulate their relationship quality in adulthood.

\section{References}

Antfolk, J. (2014). Incest aversion: The evolutionary roots of individual regulation. Åbo: Åbo Akademi.

Antfolk, J., Karlsson, M., Bäckström, A. \& Santtila P. (2012). Disgust elicited by third-party incest: The roles of biological relatedness, co-residence, and family relationship. Evolution and Human Behavior, 33, 217-223. doi:10.1016/j.evolhumbehav.2011.09.005

Antfolk, J. \& Wolf, A.P., (2016). Itemising Westermarck's hypothesis: the assumptions embedded in Westermarck's explanation of human incest avoidance. In Lagerspetz, O., Antfolk, J., Gustafsson, Y., \& Kronqvist, C. (Eds.) Evolution, Human Behaviour and Morality: The Legacy of Westermarck (pp 72-84). Routledge.

Bevc I. \& Silverman I. (2000). Early separation and sibling incest. A test of the revised Westermarck theory. Evolution and Human Behavior, 21 151-161. 
Bressan, P., Colarelli, S. M., \& Cavalieri, M. B. (2009). Biologically costly altruism depends on emotional closeness among step but not half or full sibling. Evolutionary Psychology, 7(1), 147470490900700116.

Bressan, P. \& Kramer, P. (2015). Human kin detection. WIREs Cognitive Science, 6, 299-311.

Brüderl, J., K. Hank, J. Huinink, B. et al. (2017b). The German Family Panel (pairfam). GESIS Data Archive, Cologne. ZA5678 Data file Version 8.0.0, DOI: 10.4232/pairfam.5678.8.0.0

Danielsbacka, M. \& Tanskanen, A.O. (2015). The Association between Unequal Parental Treatment and the Sibling Relationship in Finland: The Difference between Full and Half Siblings. Evolutionary Psychology, 492-510.

Fessler, D.M.T. \& Navarrete, C.D. (2004). Third-party attitudes toward sibling incest: Evidence for Westermarck's hypotheses. Evolution and Human Behavior , 25, 277-294. doi:10.1016/j.evolhumbehav.2004.05.004

Hamilton, W. D. (1964). The genetical evolution of social behaviour I and II. Journal of Theoretical Biology, 7, 1-52.

Huinik, J., Brüderl, J., Nauck, B. et al. (2011). Panel Analysis of intimate relationships and family Dynamics (pairfam): conceptual framework and design. Journal of Family Research, 23, 77-101. 
Krupp, D. B., DeBruine, L. M. \& Jones, B. C. (2011). Cooperation and conflict in the light of kin recognition systems. In C. Salmon and T. K. Shackelford (Eds.), The Oxford handbook of evolutionary family psychology (pp. 345-362). New York: Oxford University Press.

Lieberman, D., \& Lobel, T. (2012). Kinship on the Kibbutz: Coresidence duration predicts altruism, personal sexual aversions and moral attitudes among communally reared peers. Evolution and Human Behavior, 33(1), 26-34.

Lieberman, D., Tooby, J. \& Cosmides, L. (2007). The architecture of human kin detection. Nature, $445,727-731$.

Mood, C. (2010). Logistic regression: Why we cannot do what we think we can do, and what we can do about it. European sociological review, 26, 67-82.

Pollet, T. V. (2007). Genetic relatedness and sibling relationship characteristics in a modern society. Evolution and Human Behavior, 28, 176-185.

Sznycer, D., De Smet, D., Billingsley, J. \& Lieberman, D. (2016). Coresidence duration and cues of maternal investment regulate sibling altruism across cultures. Journal of Personality and Social Psychology, 111, 159-177.

Talmon, Y. (1964). Mate selection in collective settlements. American Sociological Review, 29: 491-508. doi:10.1016/j.socscimed.2010.01.054 
Tanskanen, A. O. \& Danielsbacka, M. (2014). Genetic relatedness predicts contact frequencies with siblings, nieces, and nephews: Results from the generational transmissions in Finland surveys. Personality and Individual Differences, 69, 5-11.

Westermarck, E. A. (1921). The History of Human Marriage. London: Macmillan. 
Tables and figures

Table 1. Descriptive statistics ( $\mathrm{n}$ and $\% /$ mean)

\begin{tabular}{|c|c|c|c|}
\hline & $\mathrm{n}$ & \%/mean & SD \\
\hline \multicolumn{4}{|l|}{ Childhood co-residence duration with half sibling (\%) } \\
\hline No time at all & 618 & 44.6 & \\
\hline Only for a short time & 83 & 6.0 & \\
\hline Less than half of the time & 91 & 6.6 & \\
\hline More than half of the time & 193 & 13.9 & \\
\hline Entire time & 401 & 28.9 & \\
\hline Respondent's age (mean) & 886 & 29.4 & 8.22 \\
\hline \multicolumn{4}{|l|}{ Respondent's ethnic background (\%) } \\
\hline German native & 746 & 84.2 & \\
\hline Other & 140 & 15.8 & \\
\hline Respondent's years of education (mean) & 886 & 12.2 & 2.66 \\
\hline \multicolumn{4}{|l|}{ Respondent's marital status (\%) } \\
\hline Never married & 547 & 61.7 & \\
\hline Married/civil union & 291 & 32.8 & \\
\hline Divorced or widowed & 48 & 5.4 & \\
\hline \multicolumn{4}{|l|}{ Sex of respondent and sibling (\%) } \\
\hline Male and male & 278 & 20.1 & \\
\hline Female and female & 386 & 27.9 & \\
\hline Male and female & 722 & 52.1 & \\
\hline Respondent's number of siblings (mean) & 866 & 3.4 & 1.88 \\
\hline \multicolumn{4}{|l|}{ Respondent's birth order (\%) } \\
\hline Firstborns & 755 & 54.5 & \\
\hline Laterborns & 631 & 45.5 & \\
\hline Age difference between respondent and sibling (mean) & 1,386 & 10.1 & 5.65 \\
\hline Travel time distance between respondent and sibling (mean) & 1,386 & 4.3 & 2.05 \\
\hline
\end{tabular}

Notes. Basic data: Respondent's age ethnic background, years of education, marital status, number of sibling and birth order; Long format data: Childhood co-residence duration, sex of respondent and sibling, age difference and travel time distance. 


\begin{tabular}{llll}
\multicolumn{2}{l}{$\begin{array}{l}\text { Model 1: } \\
\text { Contact frequency }\end{array}$} & \multicolumn{2}{l}{ Model 2: } \\
\cline { 1 - 2 }$\beta$ & $\begin{array}{l}\text { Emotional closeness } \\
\text { Lower Upper }\end{array}$ & $\beta$ & $\begin{array}{l}95 \% \mathrm{Cl} \\
\text { Lower Upper }\end{array}$
\end{tabular}

Chilhood co-residence duration with half sibling No time at all

Only for a short time

Less than half of the time

ref

More than half of the time

Entire time

Respondent's age

Respondent's ethnic background

German native

Other

Respondent's years of education

Respondent's marital status

Never married

Married/civil union

Divorced or widowed

$\begin{array}{llllll}0.18 & -0.15 & 0.50 & 0.20 & -0.06 & 0.47\end{array}$

ref

$\begin{array}{llllll}0.69 * * * & 0.38 & 1.00 & 0.82 * * * & 0.57 & 1.07\end{array}$

$\begin{array}{llllll}1.02 * * * & 0.78 & 1.26 & 0.86 * * * & 0.66 & 1.05\end{array}$

$\begin{array}{llllll}1.52 * * * & 1.32 & 1.72 & 1.09 * * * & 0.93 & 1.26\end{array}$

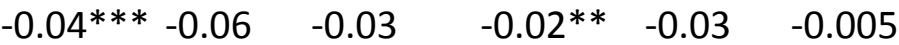

ref ref

$\begin{array}{llllll}0.06 & -0.16 & 0.29 & 0.05 & -0.14 & 0.24\end{array}$

$\begin{array}{llllll}0.04 * * & 0.01 & 0.08 & 0.04 * * & 0.01 & 0.06\end{array}$

ref ref

$\begin{array}{llllll}-0.11 & -0.34 & 0.12 & -0.16 & -0.36 & 0.03\end{array}$

$\begin{array}{llllll}-0.11 & -0.52 & 0.29 & -0.05 & -0.39 & 0.29\end{array}$

Sex of respondent and sibling

Male and male

Female and female

Male and female

ref

ref

$\begin{array}{llllll}0.27 * & 0.05 & 0.50 & 0.18 & -0.01 & 0.36\end{array}$

$\begin{array}{llllll}-0.09 & -0.28 & 0.11 & -0.03 & -0.19 & 0.13\end{array}$

Respondent's number of siblings

$\begin{array}{lll}0.01 & -0.03 & 0.05\end{array}$

$-0.02$

$\begin{array}{rr}-0.19 & 0.13 \\ -0.05 & 0.02\end{array}$

Respondent's birth order

\section{Firstborns}

Laterborns

ref

Age difference between respondent and sibling

$0.01 \quad-0.001 \quad 0.03$

ref

$\begin{array}{llll}0.03 & 0.02 * * & 0.004 & 0.03\end{array}$

Travel time distance between respondent and sibling

$-0.31^{* * *}-0.35 \quad-0.27$

$-0.08 * * *-0.11-0.04$

R2

$0.37 \quad 0.19$

Notes. ${ }^{*} \mathrm{p}<.05,{ }^{* *} \mathrm{p}<.01 .,{ }^{* * *} \mathrm{p}<.001 ; \mathrm{n}=1,386$ observations from 886 unique respondents. 
Table 3. Associations between childhood co-residence and half sibling relationship quality by sex constellation

$$
\text { Model 1: }
$$

Model 2:

Contact frequency

\section{$95 \% \mathrm{Cl}$}

Childhood co-residence duration with half sibling

$95 \% \mathrm{C}$
Lower

Emotional closeness

\section{No time at all}

Only for a short time

Less than half of the time

More than half of the time

Entire time

Sex constellation

Same-sex

Opposite-sex

Childhood co-residence $\times$ sex constellation

No time at all $\times$ sex constellation

Only for a short time $\times$ sex constellation

Less than half of the time $\times$ sex constellation

More than half of the time $\times$ sex constellation

Lower

ref

$0.01 \quad-0.48$

$-0.48$

$0.75^{\star *}$

0.30

$1.24^{* * *}$

0.91

$1.59^{* * *}$

1.33

Upper

$\frac{\text { Emotional closeness }}{95 \% \mathrm{Cl}}$

ref

$-0.14 \quad-0.36$

0.49
1.20
1.56
1.86

$\beta$

Lower

Upper

Entire time $\times$ sex constellation

ref

0.26

$-0.36$

$-0.10 \quad-0.68$

$-0.46^{*} \quad-0.90$

$-0.17$

-0.90
-0.51

ref

0.07

$1.05^{* * *}$

$-0.32$

0.47

$0.92^{* * *}$

0.69

0.65

1.41

1.86

$1.27^{* * *}$

1.05

1.49

0.38

0.07

0.003

$-0.17$

0.17

\section{R2}

$p<.001$. Covariates: Responde

of siblings, birth order, age difference and travel time distance. 
Table 4. Associations between childhood co-residence and half sibling relationship quality by sex constellation (same-sex vs. opposite-sex): Calculations based on interactions presented in Table 3

\begin{tabular}{|c|c|c|c|c|c|c|}
\hline & \multicolumn{3}{|c|}{$\begin{array}{l}\text { Model 1: } \\
\text { Contact frequency }\end{array}$} & \multicolumn{3}{|c|}{$\begin{array}{l}\text { Model 2: } \\
\text { Emotional closeness }\end{array}$} \\
\hline & \multirow[b]{2}{*}{$\beta$} & \multicolumn{2}{|l|}{$95 \% \mathrm{Cl}$} & \multicolumn{3}{|c|}{$95 \% \mathrm{Cl}$} \\
\hline & & Lower & Upper & $\beta$ & Lower & Upper \\
\hline \multicolumn{7}{|c|}{ Childhood co-residence duration with half sibling } \\
\hline No time at all & -0.14 & -0.36 & 0.07 & 0.003 & -0.17 & 0.17 \\
\hline Only for a short time & 0.12 & -0.47 & 0.71 & 0.18 & -0.30 & 0.65 \\
\hline Less than half of the time & -0.24 & -0.79 & 0.30 & -0.41 & -0.84 & 0.02 \\
\hline More than half of the time & $-0.60^{* *}$ & -0.99 & -0.22 & -0.14 & -0.45 & 0.17 \\
\hline Entire time & $-0.32^{*}$ & -0.58 & -0.05 & $-0.35^{\star *}$ & -0.56 & -0.14 \\
\hline
\end{tabular}

Notes. ${ }^{*} p<.05,{ }^{* *} p<.01 .,{ }^{* * *} p<.001$ 


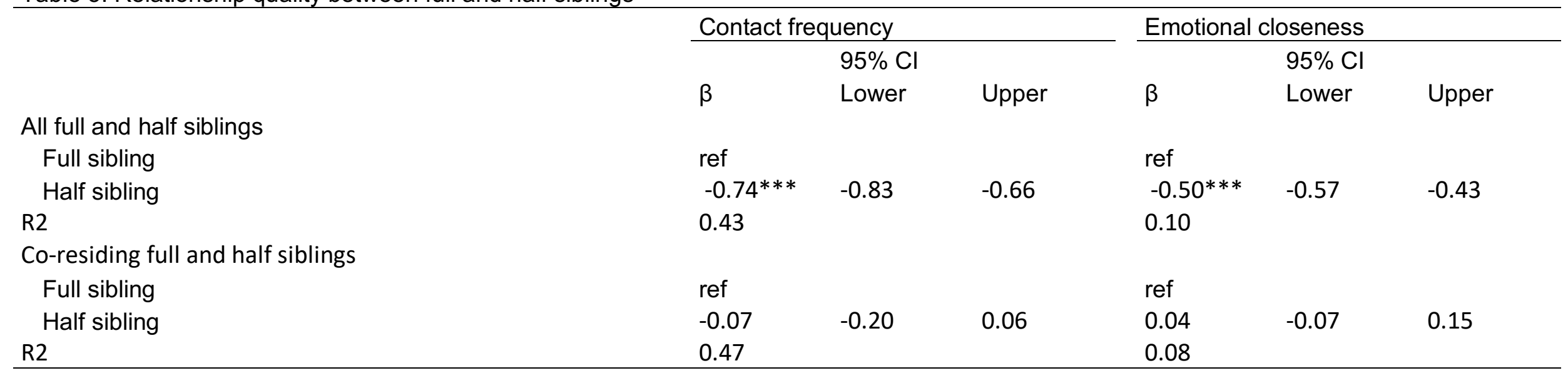

Notes. ${ }^{*} p<.05,{ }^{* *} p<.01 .,{ }^{* * *} p<.001$; All full and half siblings: $n=9,748$ observations from 5,663 unique respondents; Co-residing full and half siblings: $n=6,326$ observations from 3,814 unique respondents. Covariates: Respondent's age, ethnic background, years of education, marital status, sex of respondent and sibling, number of siblings, birth order, age difference and travel time distance. 


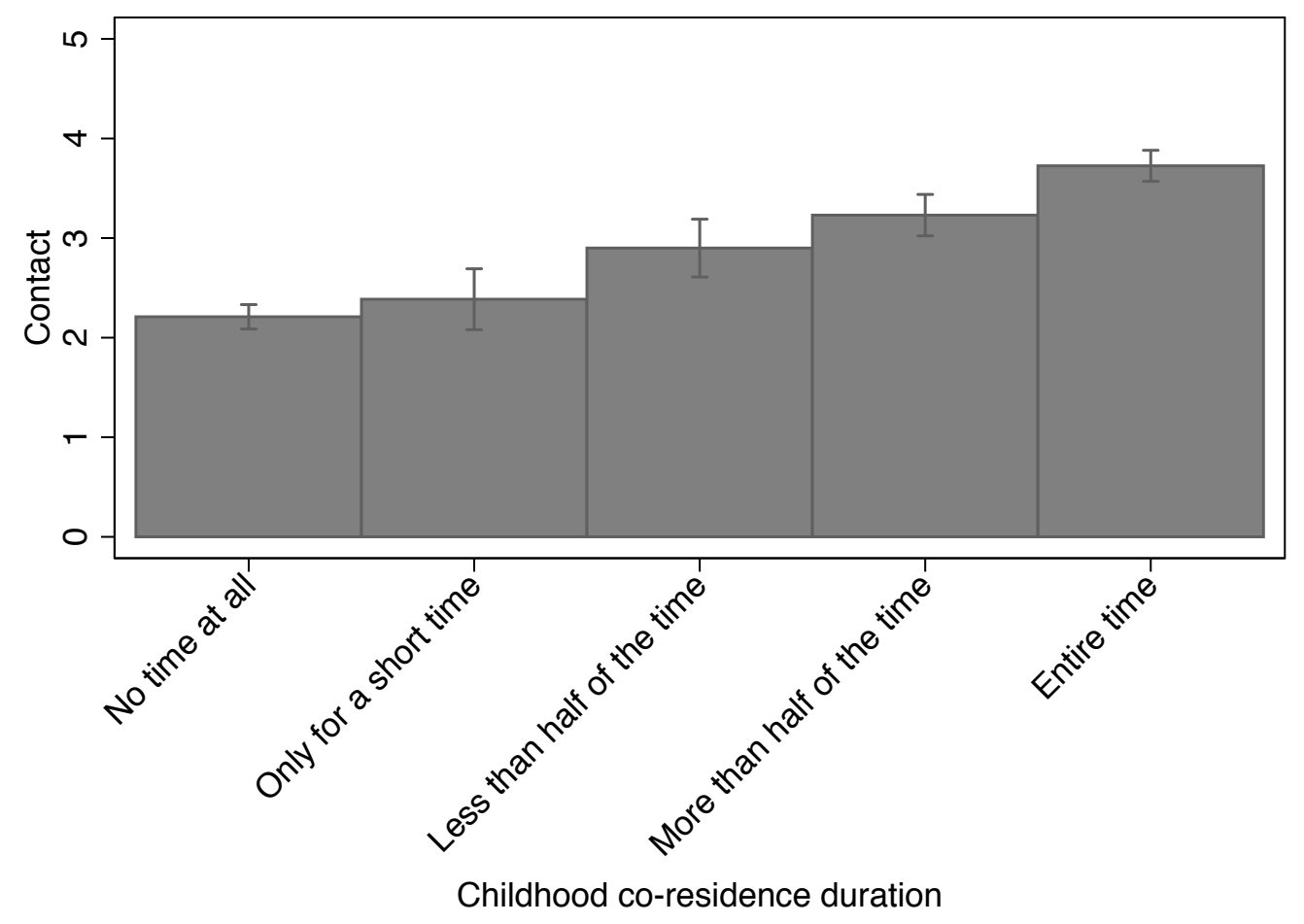

Figure 1. Association between childhood co-residence duration and half sibling contact frequency (predictive margins and $95 \%$ confidence intervals) (see Table 2: Model 1 for statistical details) 


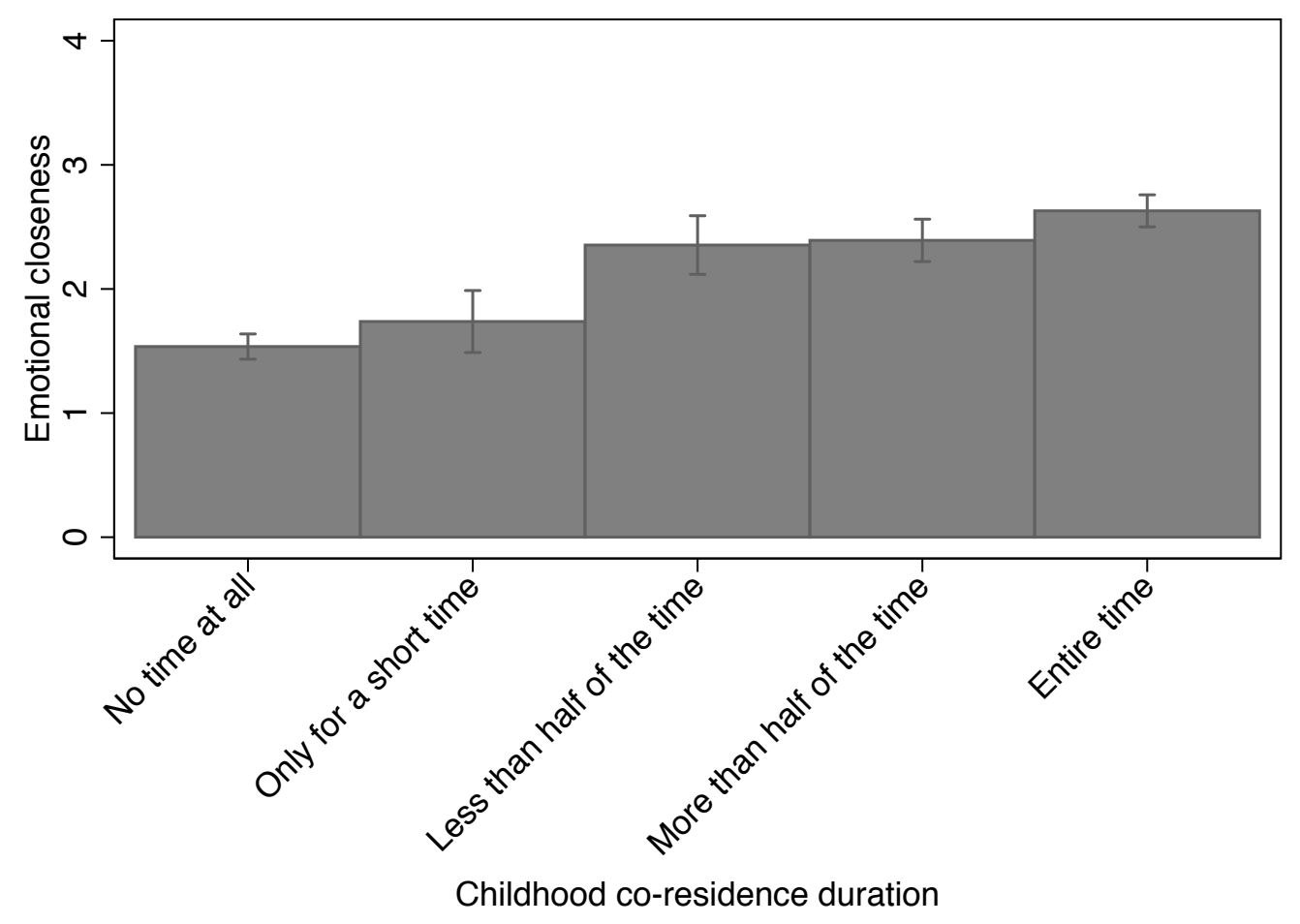

Figure 2. Association between childhood co-residence duration and half sibling emotional closeness (predictive margins and $95 \%$ confidence intervals) (see Table 2: Model 2 for statistical details) 

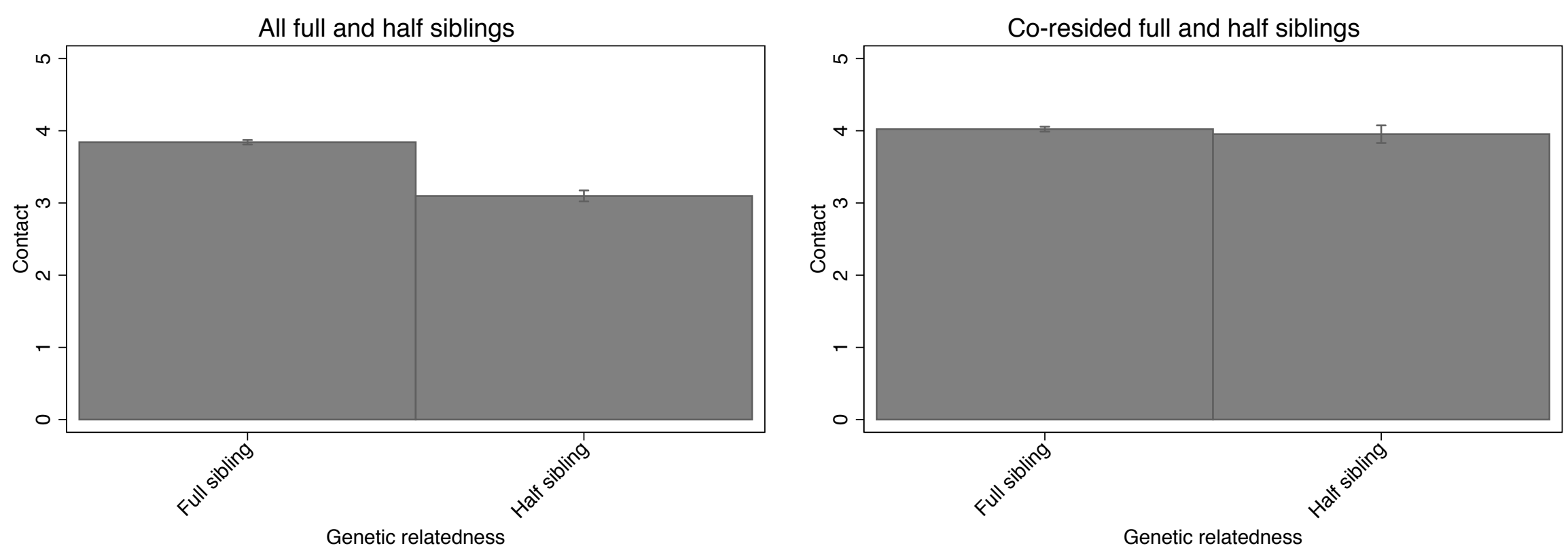

Figure 3. Contact frequency between full and half siblings (predictive margins and 95\% confidence intervals) (see Table 5 for statistical details) 

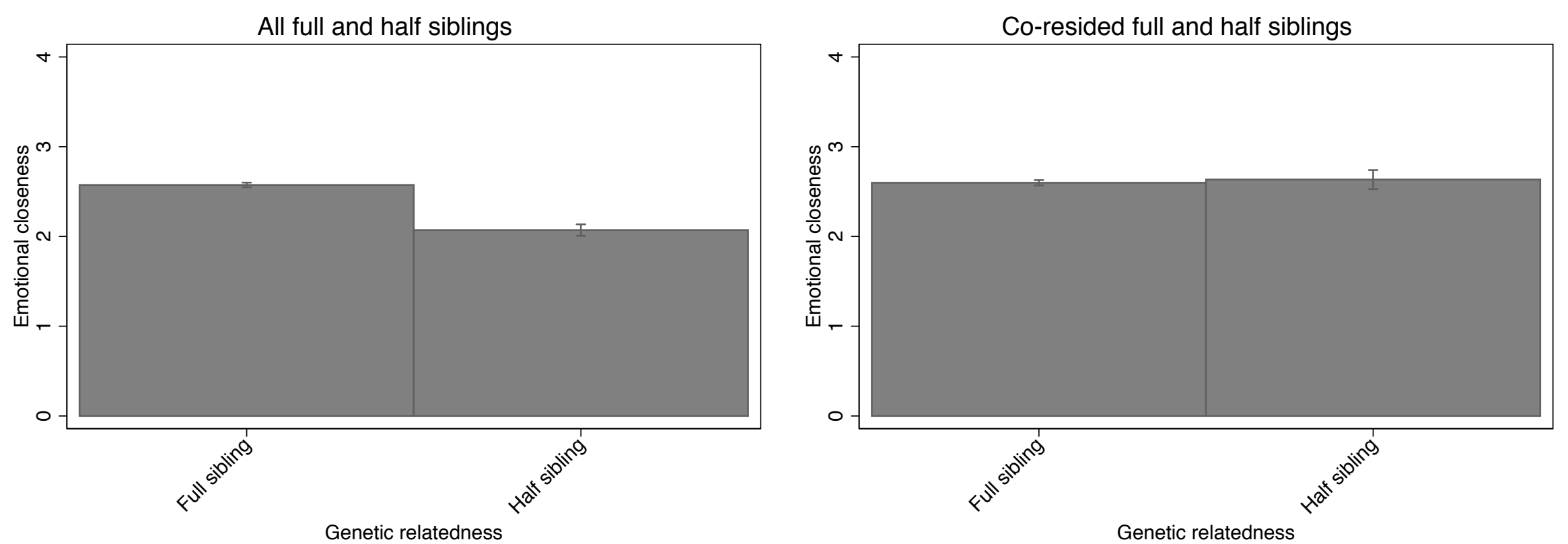

Figure 4. Emotional closeness between full and half siblings (predictive margins and 95\% confidence intervals) (see Table 5 for statistical details) 
